Int. J. Electrochem. Sci., 14 (2019) 2999 - 3010

\title{
Synthesis and Characterization of Hierarchical NiO/Ni-Co-Mn Oxide Nanocomposite Materials for High Performance Supercapacitors
}

\author{
Ziyang Qin ${ }^{1}$, Ruidong Xu ${ }^{1,2, *}$, Bohao Yu ${ }^{1}$, Wenbin Wang $^{1}$, Ying Zhang ${ }^{1}$ \\ ${ }^{1}$ Faculty of Metallurgical and Energy Engineering, Kunming University of Science and Technology, \\ Kunming 650093, China \\ ${ }^{2}$ State Key Laboratory of Complex Nonferrous Metal Resources Clean Utilization, Kunming 650093, \\ China \\ *E-mail: rdxupaper@aliyun.com
}

doi: $10.20964 / 2019.03 .47$

Received: 28 August 2018 / Accepted: 12 October 2018 / Published: 7 February 2019

Hierarchical NiO/Ni-Co-Mn oxide nanocomposite materials on nickel foam substrates were prepared by chemical bath deposition. The elemental mappings, microstructures and phase structures were observed by field-emission scanning electron microscope and X-ray diffraction, and the electrochemical properties were measured by electrochemical workstation. The grid-like $\mathrm{NiO}$ nanosheets grew directly on nickel foam substrates, thereafter $\mathrm{Ni}-\mathrm{Co}-\mathrm{Mn}$ oxide nanosheets were coated on $\mathrm{NiO}$ nanosheets to form a layered composite structure. Cyclic voltammetry analysis shows that the obvious Faradaic reactions were found and the charge could be stored quickly. The low charge transfer resistance displays that the nanocomposite structure can improve the electrochemical activity. Meanwhile, the high specific capacity (1468.14 $\mathrm{F} \mathrm{g} \mathrm{g}^{-1}$ at a current density of $1 \mathrm{~A} \mathrm{~g} \mathrm{~g}^{-1}$ ) and high cycle performance $(90.76 \%$ retention at $5 \mathrm{~A} \mathrm{~g}^{-1}$ after 3000 cycles) have been obtained by galvanostatic charge-discharge measurements. Therefore, $\mathrm{NiO} / \mathrm{Ni}-\mathrm{Co}-\mathrm{Mn}$ oxide nanocomposite material as an ideal energy storage material may be potential to use in high performance supercapacitors.

Keywords: $\mathrm{NiO}$ nanosheets; Ni-Co-Mn oxide nanosheets; chemical bath deposition; hierarchical composite structure; supercapacitor

\section{$\underline{\text { FULL TEXT }}$}

(C) 2019 The Authors. Published by ESG (www.electrochemsci.org). This article is an open access article distributed under the terms and conditions of the Creative Commons Attribution license (http://creativecommons.org/licenses/by/4.0/). 